13. Van der Geest, L. P. and Evenhuis, H. H., Tortricid Pests: Their Biology, Natural Enemies and Control, Elsevier, Amsterdam, 1991, p. 808.

14. Brown, J. W., World Catalogue of Insects, Volume 5: Tortricidae (Lepidoptera), Apollo Books, Stenstrup, Denmark, 2005, p. 741.

15. Savela, M., Lepidoptera and some other life forms, 2015; FUNET database - http://www.nic.funet.fi/pub/sci/bio/life/insecta/lepidoptera/ (accessed on 6 September 2018).

16. Meijerman, L. and Ulenberg, S. A., Arthropods of economic importance: Family Tortricidae Leafrollers: Eurasian Tortricidae. Zoological Museum, University of Amsterdam, The Netherlands, 2000 .

17. Reddy, C. S., Jha, C. S., Diwakar, P. G. and Dadhwal, V. K., Nationwide classification of forest types of India using remote sensing and GIS. Environ. Monit. Assess., 2015, 187(12), 1-30.

18. Meyrick, E., Descriptions of Indian microlepidoptera. J. Bombay Nat. Hist. Soc., 1912, 22, 160-182.

19. Deng, J., Li, K., Chen, C., Wu, S. and Huang, X., Discovery pattern and species numberof scale insects (Hemiptera: Coccoidea). Peer J, 2016, 4, e2526.

20. Gaston, K. J., Scoble, M. J. and Crook, A., Patterns in species description: a case study using the Geometridae (Lepidoptera). Biol. J. Linn., 1995, 55(3), 225-237.

21. Musthak Ali, T. M. and Ganeshaiah, K. N., Mapping diversity of ants and root grubs. Curr. Sci., 1998, 75(3), 201-204.

ACKNOWLEDGEMENTS. We acknowledge DST-SERB Core Research Grant (No. CRG/2018/000753) for funding this research work. This work is also a part of the Master's thesis submitted to Indian Agricultural Research Institute (IARI), New Delhi. We thank the Head, Division of Entomology, and the administration of IARI for support.

\section{Ethnic study on bastenga, a fermented bamboo shoot product of Nagaland, India}

\author{
Lydia Yeptho*, T. Ajungla and \\ Keviphruonuo Kuotsu \\ Department of Botany, Nagaland University, Lumami 798 627, India
}

Bamboo shoots are a local delicacy among the Naga tribe of Nagaland, India and the art of fermentation methods marks the ethnic diversity within the region. Bastenga, a fermented bamboo shoot product of Nagaland celebrates its existence in the culinary practice of tribal homes and forms an integral part of their livelihood. Womenfolk representing various tribes from different parts of the state were interviewed through questionnaires to document the traditional methods of preparation of bastenga by the various tribes. The ethnic tradition built around bastenga involves men

*For correspondence. (e-mail: yeptholydia@gmail.com) collecting tender shoots from the wild whereas the preparation involves women and children. The traditional knowledge is mostly passed from mothers to their daughters. The indigenous method of preparation varies among the different tribes, while most methods overlap. Data on gastronomy provide cumulative information across the state. The tribal communities share a common gastronomy, which further contributes to the socio-economic and cultural ethnicity of the region.

Keywords: Bamboo shoot, ethnic diversity, fermentation methods, traditional method, tribal communities.

BAMBOO serves as a minor forest produce that sustains the livelihood of tribal communities ${ }^{1}$ and the diverse use of bamboos connects the biodiversity and livelihood of a region $^{2}$. India accounts for the second largest bamboo reserve in the world and about $14 \mathrm{mha}$ is occupied by bamboo forests ${ }^{3}$. Within India, the North East states, viz. Arunachal Pradesh, Assam, Meghalaya, Manipur, Mizoram, Nagaland, Sikkim and Tripura, harbour the greatest bamboo diversity. About 58 species belonging to 18 genera are recorded in this region ${ }^{4}$. Nagaland lies between $25^{\circ} 06^{\prime}-27^{\circ} 04^{\prime} \mathrm{N}$ lat. and $93^{\circ} 20^{\prime}-95^{\circ} 15^{\prime} \mathrm{E}$ long., and covers an area of $16,579 \mathrm{~km}^{2}$. The bamboo forest cover area in this state is $4902 \mathrm{~km}^{2}$ (ref. 3) and the chief form of subsistence agriculture is shifting cultivation. Bamboo shoots are a common local delicacy in Nagaland. Some species of bamboo which are used as edible shoots are Bambussa bambos, Bambusa balcooa, Bambussa tulda, Chimonobambusa callosa, Dendrocalamus hamiltoni, Dendrocalamus hookeri, Dendrocalamus giganteus and Melocanna baccifera ${ }^{5}$. Bamboo shoots are harvested during the months of June to October and are consumed as tender shoots, sun-dried, fermented or made into pickles. Very few reports are available on the potential production, market availability and cost-benefit analysis survey of edible bamboo species ${ }^{6}$. This study aims to document the traditional methods of fermenting bamboo shoot by the various tribes in Nagaland and the gastronomy of the Nagas associated with it.

Nagaland embodies the scenic beauty of fields and terrains with a unique culture and traditions. Celebrations eulogizing folk songs and dances occurs throughout the year characterized by ebullient tribes. There are 16 major tribes and several minor tribes inhabiting the 12 districts of Nagaland. For this study, 5-7 households each were selected from Longleng, Kohima, Zunheboto, Phek, Mokokchung, Tuensang, Mon and Wokha districts of the state and the womenfolk were interviewed through questionnaires to document the traditional methods of preparation of bastenga by the various Naga tribes. Data on gastronomy provide cumulative information across the state, where the culinary and ethical values of traditional dishes cooked with bastenga (fermented bamboo shoot) and bamboo shoot have been discussed. 
Bastenga is the common name of fermented bamboo shoot in Nagaland; however it is known by various other names according to the language of each tribe in Nagaland. Regarding the origin of this name, 'bas' means 'smelly' and 'tenga' means 'sour'. Bastenga is of two
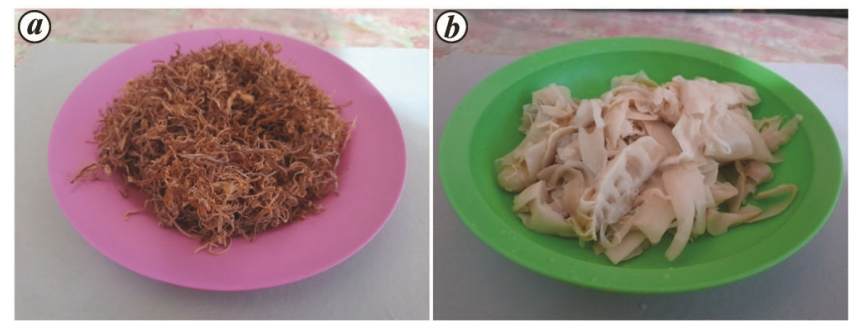

Figure 1. $\boldsymbol{a}$, Wet bastenga and $\boldsymbol{b}$, dried bastenga.
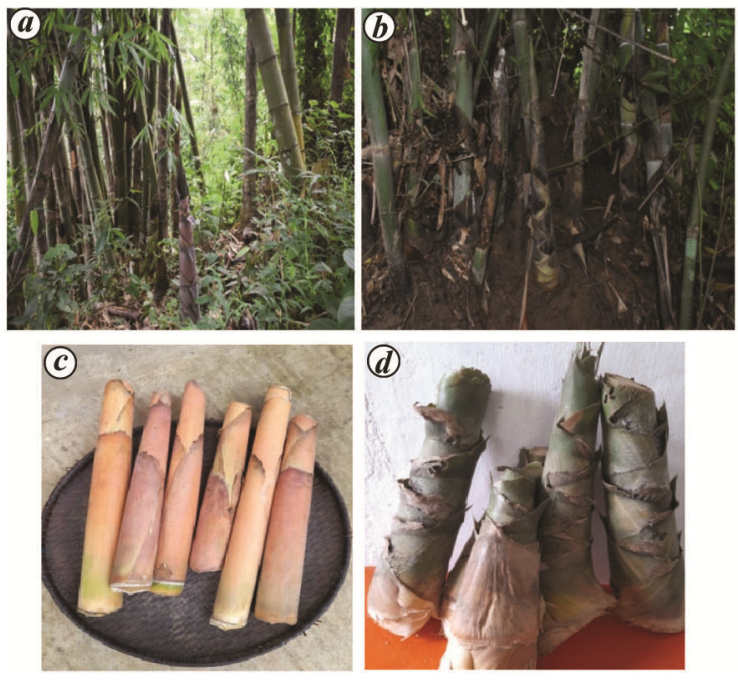

Figure $2 \boldsymbol{a}-\boldsymbol{d}$. Common bamboo species found used for preparing bastenga by the Naga tribe in Nagaland.
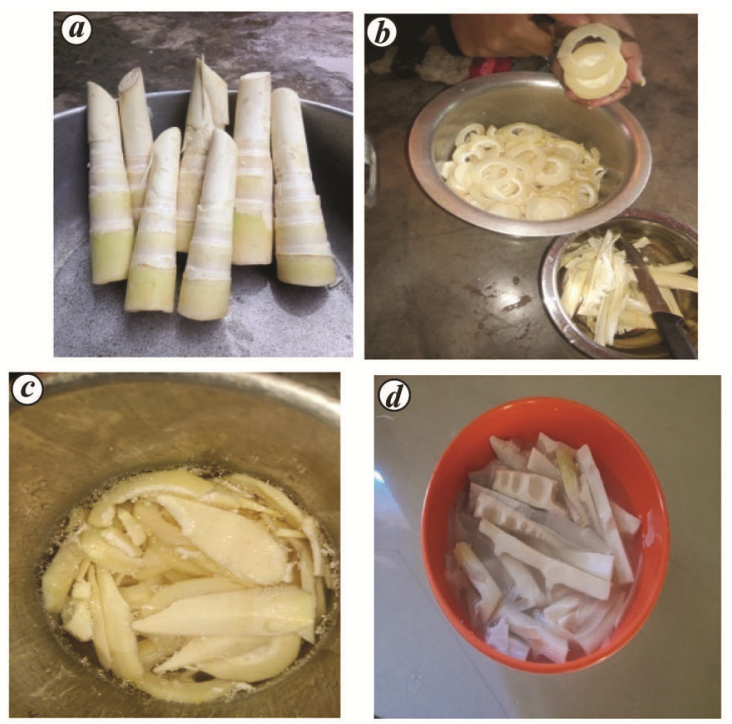

Figure $3 \boldsymbol{a}-\boldsymbol{d}$. Pictorial representation of the common traditional methods of preparing bastenga by the Naga tribe. types - dried and wet. The wet bastenga is off-white in colour (Figure 1 $a$ ), whereas dried bastenga is golden brown (Figure $1 b$ ) and both types give off a pungent smell. It is acidic in nature, $\mathrm{pH}$ is 4.7 and contains $33.07 \mathrm{~g} / 100 \mathrm{mg}$ of carbohydrates, $52.1 \mathrm{~g} / 100 \mathrm{mg}$ of protein and $0.27 \mathrm{~g} / 100 \mathrm{mg}$ of crude fibre ${ }^{7}$. A variety of edible bamboo species are used for the preparation of bastenga, which are either collected from the wild or purchased from various markets across the state. Figure $2 a-$ $d$ shows the common bamboo shoot species found in Nagaland used for preparing bastenga. The ethnic tradition built around bastenga involves men collecting tender shoots from the wild, whereas the preparation involves women and children. Thus the traditional knowledge is mostly passed from mothers to their daughters. The indigenous method of preparation varies among the different tribes and within the sub-tribes, although the methods seem to overlap. Figure $3 a-d$ shows the common traditional methods of preparing bastenga by the various Naga tribes in Nagaland.

(i) Traditional method of preparation of rhüchak by Lotha tribe of Wokha.

Tender shoots collected and sheaths removed using evo (traditional dao).

$$
\downarrow
$$

Pounded using traditional wooden mortar and pestle. $\downarrow$

Put into bamboo basket lined with banana leaves.

$$
\downarrow
$$

Container kept at the bottom to collect the juice. $\downarrow$

Left in the shade to ferment for 2-3 months.

$$
\downarrow
$$

Rhüchak (wet bastenga).

$$
\downarrow
$$

Separated and sun-dried using bamboo mats.

$$
\downarrow
$$

Rhüchon (dry bastenga).

(ii) Traditional method of preparation of akuthu by Sumi tribe of Zunheboto.

Tender shoots, with sheaths removed.<smiles>[AlH]</smiles>

Washed thoroughly and cut into thin slices.

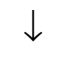

Bamboo shoot put in an airtight container filled with water.

$$
\downarrow
$$

Left to ferment in the shade for 2-3 months.$$
\downarrow
$$

Akuthu.

(iii) Traditional method of preparation of itsük by Ao tribe of Mokokchung.

CURRENT SCIENCE, VOL. 120, NO. 4, 25 FEBRUARY 2021 
Tender bamboo shoots collected, sheaths removed. $\downarrow$

Washed thoroughly and pounded (with or without the internodes).

$$
\downarrow
$$

Cone-shaped bamboo basket lined with banana leaves. $\downarrow$

Small hole made at the bottom of the basket. $\downarrow$

Container kept at the bottom to collect the juice. $\downarrow$

Left to ferment in the shade for 4-6 days. $\downarrow$

Itsük.

(iv) The Konyak tribe of Mon also follows the same method as the Ao tribe, except that the bamboo shoots are not completely pounded but slices are also added before fermentation. This is called meisong by the Konyak tribes.

(v) Traditional method of preparation of nyisam by Phom tribe of Pongching village, Longleng.

Tender bamboo shoots collected.<smiles>[AlH2]</smiles>

Culms removed and washed thoroughly. $\downarrow$

Crushed lightly and put into a bamboo basket. $\downarrow$

Covered and placed in a container at the bottom of the basket. $\downarrow$

Left to ferment in the shade for 2-3 months. $\downarrow$

Nyisam.

(vi) Traditional method of preparation of kese by Angami tribe of Kohima.

Tender shoots collected.

$$
\downarrow
$$

Sliced and placed on top of one another.

$$
\downarrow
$$

Covered with banana leaves.

$$
\downarrow
$$

Placed in a small pit in the ground.

$$
\downarrow
$$

Heavy stone placed on the top.

Fresh bamboo shoots added subsequently on the top (7-9 days).

Covered with banana leaves. $\downarrow$

Left to ferment for 6-7 months.

$$
\downarrow
$$

Kese. (vii) Traditional method practised by the Sumi tribe of Zunheboto district, Chakhesang of Phek district, Angamis of Kohima district and Eastern Naga tribe (minor tribe) of Tuensang district.

Tender bamboo shoots collected.

$$
\downarrow
$$

Sheaths removed and cleaned properly. $\downarrow$

Washed thoroughly and cut into thin slices.

$$
\downarrow
$$

Put in airtight containers.

$$
\downarrow
$$

Left to ferment in the shade for 3-6 months.

$$
\downarrow
$$

Strong smell is emitted.

$$
\downarrow
$$

Ready to consume.

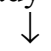

Akuthu/Kavüba/Kese.

Traditional dishes prepared by the Nagas using bastenga are as follows:

(i) Pork bastenga: This is the most popular ethnic dish of the state. Pork is prepared using spices such as ginger and garlic. The addition of bastenga enhances the flavour of the curry and gives a unique aroma.

(ii) Fish with bastenga: This is another popular dish of the Nagas. Generous amounts of bastenga and chillies along with other spices are added to prepare the curry.

(iii) Machihan: This is a famous ethnic chutney prepared by the Lothas using bastenga and chillies as a major ingredient. This dish forms a daily part of their diet and is served in all the restaurants across Wokha district.

(iv) Itsuk aon: It is an ethnic dish prepared by the Ao Nagas using fermented yam leaves and bastenga. It is also served in many restaurants across the state.

(v) Vegetable curries: Bastenga is used in almost every vegetable curry preparation. It is mostly used with potato. The brine/juice of bastenga is added while preparing vegetable curries.

Other traditional dishes using bamboo shoots are the following.

(i) Akuthu kibe. The fresh shoot is cleaned thoroughly and soaked overnight. The water is drained-off the next morning and freshwater is added again and left overnight. This process is repeated for 3-4 days. The bitterness or acidity is removed, and the bamboo shoots are cooked with Colocasia roots.

(ii) Fried bamboo shoots. The tender, fresh shoots are washed properly and cut into thin slices. They are panfried with salt and a few green chillies.

Bastenga is sold at a good price in the local markets. The Lotha tribe of Wokha prepares the best ethnic bastenga in the state. The brine or juice extracted during 
fermentation is also used as a condiment in various curries. The shelf-life of bastenga is up to 2 years, with proper measures of handling the shoots while fermenting. The Ao Naga tribe believes that use of hands should be avoided while fermenting; alternatively a spoon could be used. Also, the local people believe that only an expert should be involved in processing the bamboo shoots as the quality of the product may degrade or cause spoilage (oxidation) due to careless handling. The locals believe that bastenga has properties that neutralizes certain allergens that may be present while cooking; however, excessive use leads to stomach ailments owing to its acidic nature. The brine/juice is used as a stimulant to treat bee stings.

'Generous heart, generous plate' is the story of every Naga kitchen. Bastenga marks its popularity in the tribal homes, which is evident by the markets that continue to thrive in the region. The overlapping of traditional methods of preparation among the various tribes could be due to the availability of similar resources in the region. However, the selective taste on traditional gastronomy contributes to strengthening culinary culture and fermentation techniques in Nagaland.

Competing interests: The authors declare no conflict of interest.

1. Sundriyal, R. C., Upreti, T. C. and Varuni, R., Bamboo and cane resource utilization and conservation in the Apatani Plateau, Arunachal Pradesh, India: implications for management. J. Bamboo Rattan, 2002, 1(3), 205-246.

2. Bystriakova, N., Kapos, V. and Lysenko, I., Bamboo diversity. UNEP-WCMC/INBAR, 2004.

3. FSI, The India State of Forest Report 2011, Forest Survey of India, 2011.

4. Bhatt, B. P., Singha., L. B., Sachan, M. S. and Singh, K., Commercial edible bamboo species of the North-Eastern Himalayan Region, India. Part 1: Young shoot sales. J. Bamboo Rattan, 2004, 3(4), 337-364.

5. Kithan, L. N., Socio-economic importance of bamboo among the Nagas of Nagaland. J. Human Ecol., 2014, 48(3), 393-397.

6. Sarkar, J. and Sundriyal, R. C., Indigenous uses, management and conservation of bamboo resource in Arunachal Pradesh, North East India. Bamboo J., 2002, 19, 24-39.

7. Deb, C. R. and Jamir, B., Ethnic fermented foods and products of Nagaland, India. J. Food Chem. Nanotechnol., 2020-079.

ACKNOWLEDGEMENT. We thank the DBT, Department of Science and Technology, New Delhi for providing financial assistance under the grant No. BT/PR12956/NDB/39/504/2015. We also thank the UGC-SAP (DRS-III), DST-FIST (level 1) and the Botany Department, Nagaland University for providing the necessary facilities. We are also grateful to all the women folks interviewed for sharing their valuable knowledge and special thanks to Mr Chingmei Semdok, Miss Thejano Ngullie and Miss Elina Yeptho for their contribution during the fieldwork.

Received 25 November 2020; accepted 7 December 2020

doi: $10.18520 / \mathrm{cs} / \mathrm{v} 120 / \mathrm{i} 4 / 715-718$

\section{A new modified nutrient media for cultivation of Actinobacteria}

\author{
A. N. Ganeshamurthy*, B. Saritha, T. K. Radha \\ and P. Panneerselvam \\ Division of Soil Science, ICAR-Indian Institute of Horticultural \\ Research, Hessaraghatta, Bengaluru 560 089, India
}

The growth of Actinobacteria was evaluated in a new modified nutrient agar media (MNA) supplemented with $1 \%$ sodium chloride $(\mathrm{NaCl})$ and compared with the universally accepted media which are under regular use. Thirteen different Actinobacterial isolates were evaluated for their growth in both solid and liquid media in MNA along with four regularly used media ISP-2, kenknight, starch casein and nutrient media. Results indicated that eight isolates (Streptomyces bulli, Streptomyces griseorubens, Streptomyces viridobrunneus, Streptomyces A3, Streptomyces A7, Streptomyces A11, Streptomyces A12 and Streptomyces A13), out of thirteen isolates could grow significantly faster on MNA compared with other solid agar media. Similarly, growth in liquid media recorded by optical density (OD) indicated that three isolates (S. griseorubens, $S$. viridobrunneus and $A 7$ ) showed significantly higher OD followed by ISP-2, nutrient, starch casein and kenknight broth after seven days of incubation. All the isolates except $S$. viridobrunneus and Streptomyces A12 could tolerate $\mathrm{NaCl}$ concentration upto $6 \%$ in liquid modified nutrient broth. The present study showed that Actinobacteria can be successfully grown faster with full pigmentation at $1 \% \mathrm{NaCl}$ concentration and they can tolerate up to $5 \%$ NaCl concentration, in the new proposed MNA media.

Keywords: Actinobacteria, modified nutrient agar media, optical density, sodium chloride.

PREPARATION of suitable culture medium is one of the prerequisites to study microorganisms and for their commercial exploitation. Selection of the medium is essential for isolation and multiplication. Bacterial media can be simple or complex synthetic media, where they vary in nutritional make-up. Different microorganisms thrive at different environments and have variety of growth requirements - like $\mathrm{pH}$, osmotic conditions, nutrients and temperature. Due to lack of sufficient variability of media composition, replication of the exact environmental conditions in the laboratory and in commercial multiplication is difficult ${ }^{1}$. Several selective and differential media have been formulated, with varying components that differentiate one group of organism from another, for example, MacConkey Agar and Blood Agar. Supplementing with additional specific components, alternative media were prepared to help in further selective culturing of bacteria.

\footnotetext{
*For correspondence. (e-mail: angmurthy@gmail.com)
} 